\title{
Alasdair Macintyre's Aristotelian Business Ethics: A Critique
}

\author{
John Dobson
}

\begin{abstract}
This paper begins by summarizing and distilling MacIntyre's sweeping critique of modern business. It identifies the crux of MacIntyre's critique as centering on the fundamental Aristotelian concepts of internal goods and practices. MacIntyre essentially follows Aristotle in arguing that by privileging external goods over internal goods, business activity - and certainly modern capitalistic business activity - corrupts practices. Thus, from the perspective of virtue ethics, business is morally indefensible. The paper continues with an evaluation of MacIntyre's arguments. The conclusion is drawn that MacIntyre's critique, although partially valid, does not vitiate modern business as he claims. In short, modern business need not of necessity be antithetical to individuals' pursuit of internal goods within practices.
\end{abstract}

KEY WORDS: virtue, macintyre, capitalism

\section{Introduction}

As one of the most influential and controversial living philosophers, Alasdair MacIntyre is most well known for his book After Virtue, in which he provides a sweeping and historically based critique of modernity. His other works, of which there are many, are less well known. This is particularly true among business ethicists who, based on After Virtue, tend to dismiss MacIntyre as simply 'anti-business'. Other business ethicists attempt to usefully apply certain tenets of MacIntyre's work while avoiding his broad critique of business. However, what is lacking in the business ethics literature is any evaluative critique of MacIntyre's views on business in totem.

My purpose here is to undertake just such an evaluation. Although After Virtue is one source here, I also draw on many less-known contributions to MacIntyre's oeuvre. These latter writings, in which MacIntyre addresses specifically his views on business, provide a much richer and more nuanced picture of MacIntyre's 'anti-business' stance than can be gleaned simply from After Virtue. What I hope to show below is that MacIntyre can be more accurately characterized as a critic of a certain type of business, rather than as a critic of business per se. In addition, MacIntyre is not just a critic. He also provides a lucid alternative vision of business activity. His alternative vision is undoubtedly radical in that it essentially rejects capitalism, but it is a unified alternative vision nonetheless.

The remainder of the paper is organized as follows. First, I summarize MacIntyre's central Aristotelian thesis. Second, I critique his nuanced critique of modern business. Finally, I summarize and evaluate his radically alternative 'anti-capitalist' vision of business activity.

\section{MacIntyre's Aristotelian vision of business}

What exactly, according to MacIntyre, precludes individuals within a corporation from exercising the virtues? Why can we not have a virtuous corporation? What is it about virtue ethics that excludes competitive economic activity from the moral realm? MacIntyre, following in the tradition of Aristotle and Aquinas, answers these questions in depth. He concludes that "... the tradition of the virtues is at variance with central features of the modern economic order ..." (1984, p. 254). In the remainder of this section I endeavor to distill the essence of his argument, an argument that rests on two key concepts, namely that of a practice and of an internal good.

For an individual to successfully cultivate the virtues requires that that individual be engaged in 
a type of cooperative activity known - in virtueethics parlance - as a practice. Thus a necessary condition for a business person to be virtuous is that communal business activity qualifies as a type of practice. But does it? MacIntyre defines a practice as:

any coherent and complex form of socially established cooperative human activity through which goods internal to that form of activity are realized in the course of trying to achieve those standards of excellence which are appropriate to, and partially definitive of, that form of activity, with the result that human powers to achieve excellence, and human conceptions of the ends and goods involved, are systematically extended. (1984, p. 187)

In a similar vein Barry Schwartz (1990) isolates three central features of practices:

1. They establish their own standards of excellence, and indeed, are partly defined by those standards.

2. They are teleological, that is, goal directed. Each practice establishes a set of "goods" or ends that is internal or specific to it, and inextricably connected to engaging in the practice itself. In other words, to be engaging in the practice is to be pursuing these internal goods.

3. They are organic. In the course of engaging in the practice, people change it, systematically extending both their own powers to achieve its goods, and their conception of what its goods are.

From these definitions it is clear that the concept of an internal good is crucial to the notion of a practice. But what exactly is an internal good that distinguishes it from an external good? Here MacIntyre builds directly from Aristotle. In the Nicomachean Ethics, Aristotle begins with the fundamental observation that all human activity aims ultimately to achieve some perceived good: "Every art and every enquiry, and similarly every action and pursuit, is thought to aim at some good; and for this reason the good has rightly been declared to be that at which all things aim" (1094a19). Aristotle splits goods into internal and external. External goods are akin to the conventional goods of economics, symbolized by material wealth and what it can provide: security, honor, prestige, and power. MacIntyre defines external goods as "always some individual's property or possession. Moreover characteristically they are such that the more someone has of them, the less there is for other people. ... External goods are therefore characteristically objects of competition in which there must be losers as well as winners". (1984, pp. 190-191)

Internal goods, in contrast, are characterized by their physical intangibility. They are intrinsic satisfactions derived from some activity, and are often related to the satisfactions derived from productive crafts. Klein, for example, notes, "[t]he ideal of craftsmanship is to create that which has quality or excellence; personal satisfaction, pride in accomplishment, and a sense of dignity derived from the consequent self-development are the motivations" (1988, p. 55). Following the craft analogy, MacIntyre emphasizes the communal nature of internal goods: "The aim internal to such productive crafts, when they are in good order, is never only to catch fish, or to produce beef or milk, or to build houses. It is to do so in a manner consonant with the excellences of the craft, so that not only is there a good product, but the craftsperson is perfected through and in her or his activity" (1994, p. 284). Chytry draws the distinction between the craftwork and the commodity: "what immediately distinguishes the craftwork from the commodity is the former's imbeddedness not so much in profit or value-creation motivations as in what used to be celebrated as a 'calling' (Beruf) or vocation" (Chytry, 2007, p. 42).

This notion of a calling or vocation recognizes the moral dimension of internal goods. A dimension emphasized in Kekes's general definition of internal goods as "satisfactions involved in being and acting according to our conceptions of good lives. ... internal goods are satisfactions involved in the successful exercise of some of our dispositions in the context of a way of life to which we have committed ourselves" (1988, p. 656). In a similar vein, MacIntyre relates internal goods to the concept of a practice: "Internal goods are indeed the outcome of competition to excel, but it is characteristic of them that their achievement is a good for the whole community who participate in the practice" (1984, pp. 190-191). 
Thus, in summary, internal goods possess three distinct features:

1. They are unique to a particular activity. For example, in the context of chess, MacIntyre talks of "those goods specific to chess, ... the achievement of a certain highly particular kind of analytical skill, strategic imagination and competitive intensity ..." (1984, p. 188). Thus the internal goods to be derived from chess are different from those to be derived from accountancy, from badminton, or from architecture. Fame, power, and money, therefore given their ubiquitous nature - are clearly not internal goods.

2. They are not of finite supply. Thus my achievement of any given internal good in no way inhibits your achievement of similar goods.

3. They are intangible in the sense that they do not readily lend themselves to quantification or enumeration. This may explain why they have been largely ignored by traditional economic theory. ${ }^{1}$

As MacIntyre argues in After Virtue, it is a corporation's focus on external goods - on the goods of effectiveness over and above the goods of excellence - that disqualifies it as a practice. A virtuous corporation could not have an ultimate goal of economic gain: "It is of the character of a virtue that in order that it be effective in producing the internal goods which are the rewards of the virtues it should be exercised without regard to consequences" (MacIntyre, 1984, p. 198).

Some business ethicists note that the corporation is a type of community, and they surmise from this that it is an environment suitable for virtue ethics. For example Solomon states that "[c]orporations are real communities, neither ideal nor idealized, and therefore the perfect place to start understanding the nature of the virtues" (Solomon, 1992, p. 325). What, according to MacIntyre, this view fails to recognize is that the very nature of competitive economic activity requires a primary focus on external goods in order to survive. This focus will exclude the virtues. As MacIntyre admits, "possession of the virtues may perfectly well hinder us in achieving external goods ... [w]e should therefore expect that, if in a particular society the pursuit of external goods were to become dominant, the concept of the virtues might suffer at first attrition and then perhaps something near total effacement" (1984, p. 196).

Thus it is not just that the virtues are incompatible with capitalistic business, but also that such business actually tends to drive out the virtues. To illustrate this, MacIntyre depicts a 'modern' fishing community:

A fishing crew may be organized as a purely technical and economic means to a productive end, whose aim is only or overridingly to satisfy as profitably as possible some market's demand for fish. Just as those managing its organization aim at a high level of profits, so also the individual crew members aim at a high level of reward. ... When however the level of reward is insufficiently high, then the individual whose motivations and values are of this kind will have from her or his own point of view the best of reasons for leaving this particular crew or even taking to another trade. ... [M]anagement will from its point of view have no good reason not to fire crew members, and owners will have no good reason not to invest their money elsewhere. (1994, p. 285)

Here MacIntyre is describing contemporary business. The above is clearly an organization pursuing external goods in a competitive market economy. This is not a virtuous fishing crew. Specifically, MacIntyre isolates three "central features of the modern economic order" that exclude it from the virtues. These are "individualism ... acquisitiveness and its elevation of the values of the market to a central social place" (1984, p.254). As a consequence, the actors within modern firms, namely managers, compartmentalize themselves within the confines of a morally stunted version of utilitarianism, namely cost-benefit analysis. The milieu of the modern firm renders them blind to considerations beyond the financial 'bottom line.'

For example, in Utilitarianism and Cost-Benefit Analysis, MacIntyre observes that "once the executive is at work the aims of the public or private corporation must be taken as given. Within the boundaries imposed by corporate goals and legal constraints the executive's own tasks characteristically appear to him as merely technical ... [the] moral considerations underlying cost-benefit analysis 
are simply suppressed" (1977, pp. 218 and 237). Similarly, in Social Structures and their Threats to Moral Agency, MacIntyre discusses "a business corporation whose chief executive officer decides to exaggerate the progress made by the corporation's scientists on a research project, with the aims both of not losing customers to rivals and of bolstering share prices" (1999b, p. 322). MacIntyre argues that the "only grounds on which objection to such deception can be based, if it is to be heard, is that in the longer run deception will fail to maximize corporate profits" (p. 323).

Similarly, in After Virtue, in listing managers along with therapists and aesthetes - as one of the principal 'characters' of modernity, MacIntyre argues that managers "conceive of themselves as morally neutral characters whose skills enable them to devise the most efficient means of achieving whatever end is proposed. Whether a given manager is effective or not is on the dominant view a quite different question from that of the morality of the ends which his effectiveness serves or fails to serve" (1984, p. 74). And finally, in Why are the Problems of Business Ethics Insoluble?, MacIntyre returns solidly to the theme of compartmentalization: "With one part of the self one is a corporate executive understanding every project in terms of a suitably narrow conception of cost-benefit analysis and ignoring large side effects of one's activity. ... Effectiveness in organizations is often both the product and the producer of an intense focus on a narrow range of specialized tasks which has as its counterpart a blindness to other aspects of one's activity" (1982, pp. 357-358).

Another related criticism that MacIntyre levels against the modern firm is that of myopia: "The failure to be responsible for the future is not just a product of the negligence of individuals, but is rooted in the forms and tendencies of organizational and corporate life" (1982, p. 357). He connects this to the narrow focus on cost-benefit analysis, which he believes forces managers to set arbitrary, and likely short-term, horizons; "in a private profit-seeking corporation the current rates of return expected on investment will place constraints on such a choice of dates ..." $(1977$, p. 232). This is further reflected in his depiction of the modern fishing crew above: the managers readily "invest their money elsewhere" when the fish stocks decline.
More broadly, in Corporate Modernity and Moral Judgment: Are They Mutually Exclusive?, MacIntyre lists "four ways the moral structure of the modern corporate world can be defined by negation - by the striking absence of honor, of blasphemy, of ceremonial death, and of the story-telling elders" (1979, p. 134). Corporate modernity, according to MacIntyre, lacks a sense of "cosmic order" (ibid., p. 133) in which communal narrative, communal recognition of birth and death, communal belief in the divine, and a communal sense of honor and insult can all play significant roles. And more recently MacIntyre has continued this criticism by asserting, in Dependant Rational Animals, that marketbased relationships such as those within and between modern firms "undermine and corrupt communal ties" (1999a, b, p. 117).

\section{Evaluating MacIntyre's Aristotelian business ethics}

Is MacIntyre correct? Does the modern firm within capitalism induce compartmentalization and myopia? Do the managers of modern firms frame every decision in terms of a narrowly defined cost-benefit analysis? Do they leave moral agency at the door when they enter the boardroom?

Although the picture MacIntyre paints of modern business undoubtedly illustrates many of the characteristics of contemporary corporate culture, he paints with very broad brush-strokes. Modern firms and the managers therein undoubtedly exhibit the shortcomings that MacIntyre highlights. But the evidence indicates that these firms and individuals exhibit the shortcomings to a greater or lesser degree. Also, these enterprises exhibit other, more morally desirable, characteristics that are not consistent with MacIntyre's characterization. In short, for reasons summarized below, MacIntyre's view may be too narrow.

First, many managers do in fact devote nonsuperficial moral reflection to their role as managers. This is evidenced by the many ongoing ethics lecture-series held at many business schools in which managers typically discuss their on-the-job moral deliberations. These belie Macintyre's claim that "there is no milieu available to them [managers] in which they are able, together with others, to step 
back from those roles and those requirements and to scrutinize themselves and the structure of their society from some external standpoint with any practical effect" (1999b, p. 322).

It is not even necessary to look at the businessethics evidence. If we restrict ourselves to the observations of writers who have no explicit concern with ethics, we still find compelling evidence that MacIntyre's rendition of the modern firm - and the compartmentalized manager therein - is too narrow. In The Modern Firm: Organizational Design for Performance and Growth, John Roberts begins with the statement: "The most fundamental responsibilities of general managers are setting strategy and designing the organization to implement it" (2004, p. ix). He goes on to state that "Firms are institutions created to serve human needs ... to provide meaningful experiences" (p. 18). He recognizes that this cannot be achieved by applying only explicit criteria (such as cost-benefit analysis), evaluative criteria such as corporate culture are equally important: "Culture is the 'softer' stuff, but it is not less important for that. It involves the fundamental shared values of the people in the firm, as well as their shared beliefs about why the firm exists, about what they are collectively and individually doing, and to what end" (p. 18). Note well that, in contradiction to MacIntyre's assertion, Roberts observes that managers do not take ends as given. It is also noteworthy that Roberts bases his observations on experiences gained from "the executives and managers at the many companies I have been able to visit and study, especially BP, General Motors, Johnson Controls, Nokia, Novo Nordisk, Sony, and Toyota" (p. xi). For example, in the case of Nokia: "People were simply expected to do their best and were trusted to act in the best interests of the company ... employees throughout the firm were motivated by the desire to save the company. The successes they collectively achieved were a source of real pride." (pp. 174 and 276).

This description is strikingly similar to MacIntyre's prescription that the "aim internal to such productive crafts, when they are in good order, is never only to catch fish, or to produce beef or milk, or to build houses. It is to do so in a manner consonant with the excellences of the craft, so that not only is there a good product, but the craftsperson is perfected through and in her or his activity" (1994, p. 284).
So, in a book that never even mentions ethics, Roberts observes the modern firm creating and nurturing what MacIntyre argues it is quintessentially incapable of creating and nurturing: namely practices. Roberts's experiences reveal a management psychology far deeper and more nuanced than merely a rigid application of cost-benefit analysis as MacIntyre suggests. Indeed, Roberts concludes his book by observing that "solving the problems of strategy and organization is an act of real creativity" (p. 286).

As with Roberts, Michael Jensen resides firmly in the camp of a financial-economic perspective on the firm. But, on the few occasions when Jensen does venture into a broad discussion of the nature and purpose of business, we again find prescriptions strikingly similar to MacIntyre's utopian practicenurturing institution: "Value maximization is not a vision or a strategy or even a purpose; ... people ... must be turned on by the vision or the strategy in the sense that it taps into some human desire or passion of their own - for example, a desire to build the worlds best automobile or to create a film or play that will move people for centuries" (2001, p. 16). So here we see Jensen, albeit inadvertently, making a distinction that can readily be seen as analogous to that of internal and external goods; and note well that for Jensen the internal goods are the motivator and the external goods the way of 'keeping score.' He continues:

Value seeking tells an organization and its participants how their success in achieving a vision or in implementing a strategy will be assessed. But value maximizing or value seeking says nothing about how to create a superior vision or strategy. Nor does it tell employees or managers how to find or establish initiatives or ventures that create value.... Defining what it means to score a goal in football or soccer, for example, tells the players nothing about how to win the game. [Ibid]

Jensen's soccer example invites parallels to MacIntyre's discussion of the internal goods of chess: "those goods specific to chess, in the achievement of a certain highly particular kind of analytical skill, strategic imagination and competitive intensity" (1984, p. 187). (And note well in passing that MacIntyre views 'competitive intensity' - a foundational principle of capitalism - as an internal good.)

Finally from Jensen: "we must give employees and managers a structure that will help them resist 
the temptation to maximize short-term financial performance ... short-term profit maximization at the expense of long-term value creation is a sure way to destroy value" (op cit). This belies MacIntyre's claim that capitalism necessarily promotes myopia. As Hart observes, "the firm must not only perform efficiently in today's businesses, but it should also be constantly mindful of generating the products and services of the future. This means developing or acquiring the skills, competencies, and technologies that reposition the firm for future growth. ... A convincing articulation of how and where the firm plans to grow in the future is crucial to the generation of shareholder value" (2007, pp. 63-64). So whether involved in fishing, farming, computer software development, or all three, the modern firm's outlook is far from arbitrary or myopic. Indeed, archeological evidence indicates that - at least in the context of natural resource depletion pre-modern communities were the real sufferers from myopia: "American Indians often so pressured or depleted basic resources like land and trees that they had to switch from one type of food to another or move the locations of their villages" (Krech, 1999 , p. 76); similarly, the indigenous pre-modern culture of Easter Island collapsed when all the trees on the island were felled (ibid.).

\section{Conclusion}

Returning to MacIntyre's depiction of fishing crews, in contrast to the modern fishing enterprise described above, MacIntyre conjures another 'Aristotelian' fishing community:

Consider by contrast a crew whose members may well have initially joined for the sake of their wage or other share of the catch, but who have acquired from the rest of the crew an understanding of and devotion to excellence in fishing and to excellence in playing one's part as a member of such a crew. ... So the interdependence of the members of a fishing crew in respect of skills, the achievement of goods and the acquisition of virtues will extend to an interdependence of the families of crew members and perhaps beyond them to the whole society of a fishing village. (1994, p. 285)

Where might such communities actually exist, or have existed? MacIntyre gives several examples:
Fishing communities in New England, Welsh mining communities, farming coops in Donegal, Mayan towns in Guatemala and Mexico, ancient Greek city states, Greek highland villages, medieval Christian and Arab kingdoms, Scottish highland clans before 1600 , the Sioux nation, Bedouin of the Western desert, and the Irish of the Blasket Islands? (1982, and 1999a).

But these examples reflect again the 'broad-brush' characteristic of MacIntyre's vision. Although the above communities undoubtedly possess or possessed desirable attributes, they also undoubtedly possessed many undesirable attributes. A focus on internal goods, in and of itself, is not sufficient to render a community utopian, or even desirable. Many members of these communities, particularly those not in the power elite, were no doubt happy to leave them behind and embrace capitalist modernity. As Frazer and Lacey note: "Feminist theory understands male power exercised and maintained in and through practices" (1994, p. 271).

In Dependant Rational Animals, MacIntyre argues that utopia would be "inimical to and in conflict with the goals of a consumer society" (1999a, p. 145). But as Keat recently pointed out, "although the acquisition of consumer 'goods' takes place through exchange within the market (or economic) domain, the realization of their value typically takes place in non-market domains" (2007, p. 6, his emphasis). For example, if I wish to pursue the internal goods of chess, the market will not prevent me from whittling my own chess pieces from a piece of walnut if I so choose; but what it will do is present me with a dizzying array of alternative chess sets; not to mention some very sophisticated non-human opponents. But note well the choice to participate in the 'consumer society' is mine.

MacIntyre describes utopia in terms of "rejecting the economic goals of advanced capitalism" (1999a, p. 145). But his logic rests on the premise that these economic goals corrupt other non-economic goals - the types of goals people had in premodernity. But the evidence does not support this premise; in fact it indicates the opposite. There is now available a wealth of evidence to indicate that it is precisely advanced capitalism in general and the modern firm in particular that has engendered human flourishing. This evidence indicates a high correlation between health, wealth, and happiness 
for all demographic groups (Baumol et al., 2007; Hart, 2007; Layard, 2005). And this includes the elderly and disabled; the latter being groups MacIntyre is particularly concerned about in Dependant Rational Animals. Also, in The Moral Consequences of Economic Growth (2005), Friedman provides solid evidence to indicate that one essential ingredient for communal moral health and happiness is economic growth.

This is not to say that the modern firm, embraced by capitalism, is perfect in the sense of always nurturing internal goods within practices. But it at least has provided unparalleled material wealth as a foundation for practices. Capitalism is also flexible and continually evolving. MacIntyre's critique might be better used as a source of direction for this evolutionary process, rather than - as MacIntyre himself tends to use it - as a 'call-to-arms' for capitalism's destruction.

\section{Note}

1 Recently, however, even economists are more readily recognizing notions of internal or intrinsic motivation and satisfaction: Kreps, for example, challenges economists' conventionally -assumed inverse relation between effort and utility when he suggests that "[w]orkers may take sufficient pride in their work so that effort up to some level increases utility" (1997, p. 361). He acknowledges that this calls into question conventional notions of motivation: "Answers involve looking into the utility functions of individuals, terra incognito for standard microeconomics" (p. 361). Sen, who does venture into this terra incognito, warns of the dangers "imposed by taking an overly narrow view of human motivation" (1997, p. 750f).

\section{References}

Baumaol, W. J., R. E. Litan and C. J. Schramm: 2007, Good Capitalism Bad Capitalism (Yale University Press, New Haven).

Chytry, J.: 2007, 'Organizational Aesthetics: The Artful Firm and the Aesthetic Moment in Contemporary Business and Management Theory', Working Paper, University of California, Berkeley.

Frazer, E. and N. Lacey: 1994, 'MacIntyre, Feminism and the Concept of Practice', in J. Horton and S. Mendus (eds.), After MacIntyre: Critical Perspectives on the Work of Alasdair MacIntyre (University of Notre Dame Press, Notre Dame).

Friedman, B.: 2005, The Moral Consequences of Economic Growth (Knopf, New York).

Hart, S.: 2007, Capitalism at the Crossroads (New Jersey: Wharton School Publishing).

Jensen, M. C.: 2001, 'Value Maximization, Stakeholder Theory, and the Corporate Objective Function', Social Science Research Network Electronic Paper Collection.

Keat, R.: 2007, 'Ethics, Markets and MacIntyre', Paper for the Conference on Alasdair MacIntyre's Revolutionary Aristotelianism, HRSJ Research Institute, London Metropolitan University, 29th June to 1st July.

Klein, S.: 1988, 'Is a Moral Organization Possible?', Business \& Professional Ethics Journal 7(1), 51-73.

Krech, I. I. I. S.: 1999, The Ecological Indian (New York: Norton paperbacks).

Kreps, D.: 1997, 'Intrinsic Motivation and Extrinsic Incentives', The American Economic Review 87(2), 359364.

Layard, R.: 2005, Happiness: Lessons from a New Science (Penguin Press, New York).

MacIntyre, A.: 1977, 'Utilitarianism and Cost-Benefit Analysis: An Essay on the Relevance of Moral Philosophy to Bureaucratic Theory', in K. Sayre (ed.), Values in the Electric Power Industry (University of Notre Dame Press, Notre Dame).

MacIntyre, A.: 1979, 'Corporate Modernity and Moral Judgment: Are they Mutually Exclusive?', in K. E. Goodpaster and K. M. Sayer (eds.), Ethics and Problems of the 21st Century (University of Notre dame Press, Notre Dame).

MacIntyre, A.: 1982, 'Why are the Problems of Business Ethics Insoluble', in B. Baumrin and B. Friedman (eds.), Moral Responsibility and the Professions (Haven Publishing, New York).

MacIntyre, A.: 1984, After Virtue, 2nd Edition (University of Notre Dame Press, Notre Dame).

MacIntyre, A.: 1994, 'A Partial Response to my Critics', in J. Horton and S. Mendus (eds.), After MacIntyre: Critical Perspectives on the Work of Alasdair MacIntyre (University of Notre Dame Press, Notre Dame).

MacIntyre, A.: 1999a, Dependant Rational Animals (Open Court Publishing, Illinois).

MacIntyre, A.: 1999b, 'Social Structures and Their Threat to Moral Agency', Philosophy (London, England) 74(289), 311-329.

Roberts, J.: 2004, The Modern Firm: Organizational Design for Performance and Growth (Oxford University Press, Oxford). 
Schwartz, B.: 1990, 'King Midas in America', in C. C. Walton (ed.), Enhancing Business Ethics (Plenum Press, New York).

Sen, A.: 1997, 'Maximization and the Act of Choice', Econometrica 65, 745-779.

Solomon, R. C.: 1992, 'Corporate Roles, Personal Virtues: An Aristotelian Approach to Business Ethics', Business Ethics Quarterly 2, 317-339. doi:10.2307/ 3857536.
Finance, College of Business, California Polytechnic State University, San Luis Obispo, CA 93407, U.S.A. 